\title{
Knowledge and Practice of Postnatal Mothers on Newborn Care at Hospital Setting
}

\author{
Sushila Devi Bhandari \\ Associate professor, \\ Nepalese Army Institute of Health Sciences, \\ College of Nursing, Bhandarkhal, Sanobharyang, Kathmandu, \\ ya_su_sa@hotmail.com \\ Saraswati Sharma, Paudyal \\ Associate Professor,
}

\begin{abstract}
:
Introduction: Even thoughthe neonatalmortality is declined in the country, stillthe neonatal morbidity and mortality rate is very high.Newborn survival is very important to improve the newborn health and for to achieve the millennium developmental goals. It will be possible by increasing awareness and appropriate practices of mothers towards newborn care.

Objective: The objective of this study is to explore the knowledge and practice of mother on newborn care.

Methodology: Descriptive cross sectional study was conducted. A pretested, semi structured interview schedule was used to assess knowledge and check list was used to assess the practice of 75 purposively selected post natal mothers admitted in MahendraAdarsa Hospital, Chitwan. SPSS 21 version was used to analysis the data.

Results: The study shows that $38.7 \%$ respondents hadgood knowledge, $41.3 \%$ had moderate knowledge and $20 \%$ had poor knowledge about newborn care and $73.3 \%$ of respondents had adequate practice, $26.7 \%$ had inadequate practice related to newborn care. Relationship between knowledge and practice score of the mother was not statistically significant at 0.05 level $(P=0.377)$. The education of the mothers had significantly associated with the practice of the mother regarding new-born care $(p=0.047)$.
\end{abstract}

Conclusion: Majority of the post-natal mother had knowledge and adequate practices on newborncare.

Keywords: Knowledge, New born, Newborn Care, Postnatal Mothers, Practice

\section{INTRODUCTION}

Globally 4 million newborn die every year before they reach the age of one month. Out of them 1.5 million newborn die in four countries of South Asia including Nepal (WHO, 2006). Approximately 3.4 million newborn die within the first week of life. Of these deaths, $66 \%$ occur during the $1^{\text {st }} 24$ hours. Late death i.e.; after 24 hours, still occur $34 \%$ and may be prevented if mothers have knowledge about newborn care including dangers sign of newborn (Thakur, 2012).

Clean cord care is one of the essential newborn care practices recommended by the World Health Organization to reduce morbidity and mortality amongst the World's newborns. Despite this, cord infections are still prevalent in developing countries because of the high rates of unhygienic cord care practices (Opara, Jaja, Dotimi, \& Alex Hart, 2011).

The care the newborn receives depends a lot on the knowledge, skills and attitude of the mother. The primigravida mothers are supposed to be lacking in knowledge, practices and attitude of newborn care (Yadav, 2013).

Comparing data with result of 2006 under-five mortality rates have declined over the past, but the neonatal mortality rates still remains high.ie; IMR- 48/1000 live birth and NMR 33/1000 live birth (NDHS,2011). Awareness and attitude of postnatal mothers towards neonatal care has lots of lacunae especially in those who belong to the lower socio- economic status. There is scope for improvement 
by providing better care and health education for antenatal mothers (Monebenimp, Mireille, Chelo, Pascal, Christopher, \& Charles, 2013).

Neonatal health and survival is enhanced by providing essential newborn care such as cleanliness, thermal protection, and initiation of breathing, early and exclusive breastfeeding, eye care, immunization, and management of newborn illness. Mothers are the key person for providing newborn care in Nepal (Shrestha, Gautam, \& Silwal, 2013). So that study was conducted to assess the knowledge and explore the practice of postnatal mother regarding new born care.

\section{Methods AND Materials}

This study was descriptive cross sectional study. Purposive sampling technique was used to select the sample as well as study site. After getting permission from hospital and informed verbal consent from each respondent, face to face interview was conducted with 75 postnatal mothers admitted in post natal ward of MahendraAsarsa Hospital,Chitwan, Nepal from August 2014 to November2014.Both primi and multi gravid postnatal mothers were included in the study to explore knowledge on newborn care and practice was observed in 30 post natal mothers.

Semi- structured interview schedule was used for face to face interview to assess the knowledge and observation check list was used to assess the practice of mothers regarding new born care. Respondents were assured that the information provided by them waskept confidential and their name was not disclosed in report.

\section{RESUltS}

Among 75 postnatal mothers,majority of group $70.7 \%$ belong to $20-27$ years of age, and minority $2.7 \%$ belong to age of 35 years and above. Majority $60 \%$ of respondents resides at rural areas. Concerning the ethnicity,62.7\% were Janajati-disadvantaged group followed by $37.7 \%$ upper cast and $89.3 \%$ of respondents were Hindu followed by $9.3 \%$ Buddhist. Regarding educational status $46.7 \%$ of respondents have studied up to Higher-Secondary Level and $2.7 \%$ have got no education.Majority $74.7 \%$ of respondent's family income has between Rs 10000 - 15000 per month. Among 75respondents, $46.7 \%$ are engage in agriculture and65. 3\% of respondents lived in joint family. Most of the respondents $65.3 \%$ were primi-para. Majority of the respondents $97.3 \%$ have attended antenatal Clinic and majority of them $66.7 \%$ have visited Antenatal clinic for 4 times.

Majority, $85.3 \%$ of respondents said that newborn means the baby up to 28 days. Regarding average weight of newborn $74.7 \%$ of respondents answered the baby should be of $3000-3500$ grams to be of normal weight. About sleep need of newborn $41.3 \%$ of respondents stated that newborn need 20-22 hrs of sleep per day.

Majority $56 \%$ of respondents answered that secretion in respiratory tract will lead to aspiration pneumonia and 5-3 \% answered Jaundice.Majority of respondents $94.7 \%$ have heard about physiological jaundice. And out of them $60.6 \%$ said that it will appear within 24 hours of birth and $18.3 \%$ said 6-8 days of birth. And $45.1 \%$ of respondents said it will disappear between 2-4 days and $38 \%$ said it will take 4-6 days.

Majority $98.7 \%$ of postnatal motherssaid newborn should be first fed with mother's milk/ colostrum. Regarding breast feeding frequency $54.7 \%$ answered she fed newborn whenever it needs.Majority $88 \%$ of respondents have heard about (Exclusive Breast Feeding) EBF. Out of 66 respondents hearing about EBF, 72.7 \% said it means feeding baby only mother's milk for 6 months.

Majority of respondents, $89.3 \%$ answered that cord should be observed for cord bleeding/ discharge, redness and for swelling around cord. Regarding, keeping cord clean majority $56.3 \%$ of respondents answered that it should be kept clean to prevent infection.

Majority $72 \%$ of respondents answered newborn should be bathed after 24 hours of birth, $88 \%$ of respondents answered clean cotton cloth is used to clean newborn eye.

Regarding oil massage, majority $89.3 \%$ of respondents said it improves blood circulation, keeps skin healthy and prevent from cold, $5.3 \%$ said it helps to increase body weight.

Regarding the maintenance of body temperature $56 \%$ of respondents said that newborn can be kept warm by covering head and chest with cotton cloth and keeping baby with mother. Regarding ways to assess body temperature majority $45.3 \%$ said by touching the forehead, $33.3 \%$ said by touching 
abdomen.Asking about Kangaroo Mother Care $74.7 \%$ of respondents said they have heard about it. Out of 56 respondents $82.1 \%$ said it means skin to skin contact of baby with mother like Kangaroo and rest $14.3 \%$ said keeping baby near mother.

While asking about the immunization, cent percent knew about it. Regarding time for $1^{\text {st }}$ immunization majority of respondents $44 \%$ answered 45 day of birth, $26 \%$ replied immediately following birth, $20 \%$ said don't know and remaining 10\% said within 1 month of birth.

Table 1. Knowledge of respondents on danger signs of newborn

\begin{tabular}{|l|c|c|}
\hline Variables & Frequency & Percent (\%) \\
\hline Baby feels too cold or very hot & 66 & 88 \\
\hline Not able to suck breast & 60 & 80 \\
\hline Yellow palm and feet & 30 & 40 \\
\hline Diarrhoea & 36 & 48 \\
\hline Vomits everything & 45 & 60 \\
\hline Breathing problems/Cyanosed & 27 & 36 \\
\hline Abnormal movement & 21 & 28 \\
\hline Swelling around umbilical cord & 15 & 20 \\
\hline Difficult to awake & 12 & 16 \\
\hline Red, swollen, and discharging eyes & 12 & 16 \\
\hline Weight loss & 12 & 16 \\
\hline Difficulty in toileting & 3 & 4 \\
\hline Pustules & 3 & 4 \\
\hline
\end{tabular}

\section{*Multiple responses}

As per above table, $88 \%$ of the women responded that the danger signs in the new born baby were that the baby felt too cold or too hot, $80 \%$ responded that the baby were not able to suck breast and $60 \%$ responded vomiting in the new born. Mean knowledge of respondents related to danger sign is 26.30 .

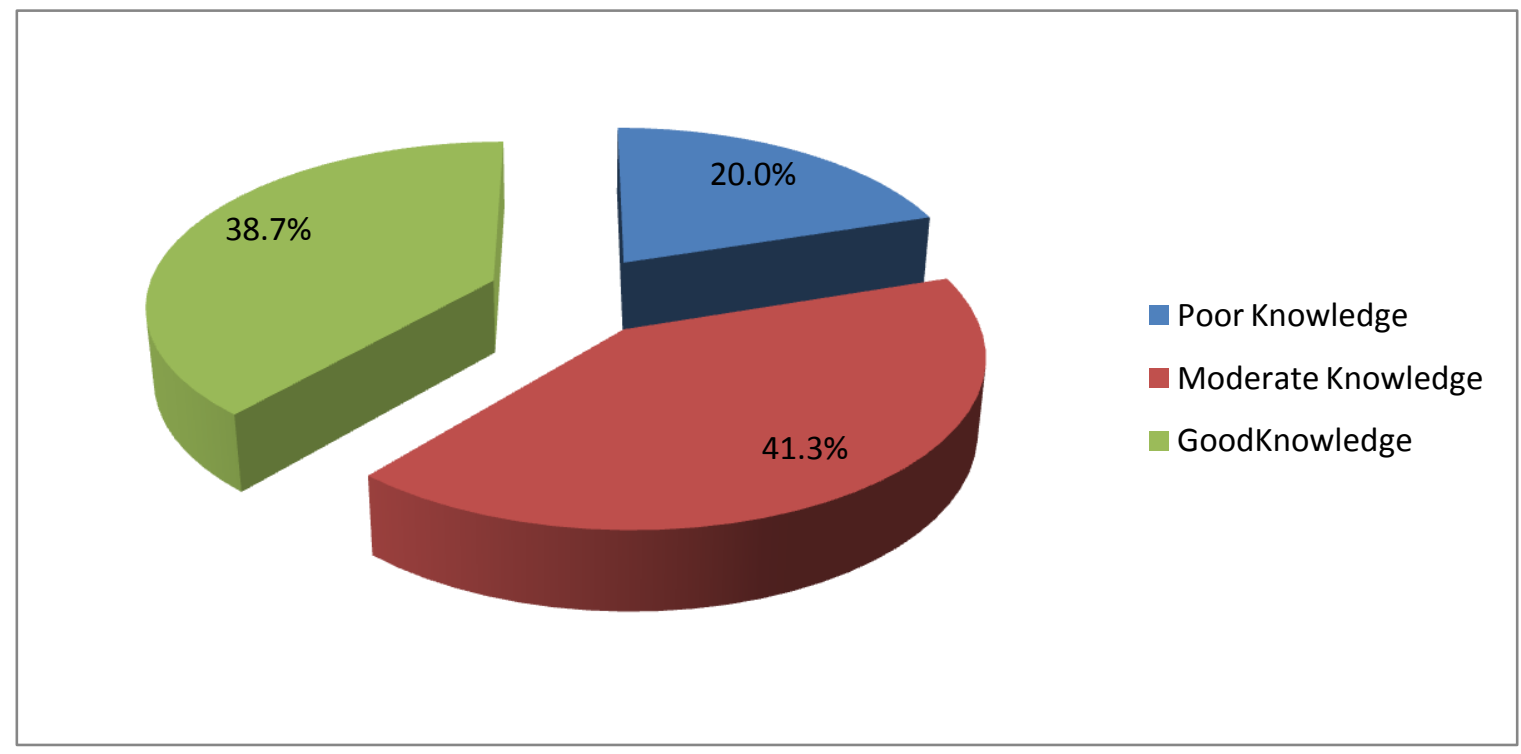

Figure 1. Level of knowledge of respondents on newborn care

Figure 1 shows that $41.3 \%$ have moderate knowledge, $38.7 \%$ of respondents have good knowledge, and $20.0 \%$ have poor knowledge related to newborn care.

Table 2. Association between knowledge and Demographic characterstics

\begin{tabular}{|l|l|c|c|c|l|}
\hline Characteristics & \multicolumn{4}{|c|}{ Knowledge on new born care } & P value \\
\hline \multirow{3}{*}{$\begin{array}{l}\text { Age of the } \\
\text { respondents }\end{array}$} & & Low & Moderate & High & $\begin{array}{l}\text { Chi square value } \\
\text { at } 2 \text { d.f .= 10.65 } \\
\text { and p value } \mathbf{0 . 1 0}\end{array}$ \\
\cline { 2 - 5 } & Below 20 & $1(10 \%)$ & $4(40 \%)$ & $5(50 \%)$ & \\
\cline { 2 - 5 } & $20-27$ & $11(20.8 \%)$ & $20(37.7 \%)$ & $22(41.5 \%)$ & $0(0 \%)$ \\
\cline { 2 - 5 } & $28-34$ & $3(30 \%)$ & $7(70 \%)$ & $2(100 \%)$ & \\
\cline { 2 - 5 } & 35 and & $0(0 \%)$ & $0(0 \%)$ & \\
\hline
\end{tabular}


Sushila Devi Bhandari \& Saraswati Sharma, Paudyal

\begin{tabular}{|c|c|c|c|c|c|}
\hline & above & & & & \\
\hline \multirow[t]{2}{*}{ Residence } & Urban & $3(10 \%)$ & $14(46.7 \%)$ & $13(43.3 \%)$ & \multirow{2}{*}{$\begin{array}{l}\text { Chi square value } \\
=3.12 \text { and } p \\
\text { value }=0.21\end{array}$} \\
\hline & Rural & $12(26.7 \%)$ & $17(37.8 \%)$ & $16(35.5 \%)$ & \\
\hline \multirow[t]{3}{*}{ Religion } & Hindu & $14(20.9 \%)$ & $24(35.8 \%)$ & $29(43.3 \%)$ & \multirow{3}{*}{$\begin{array}{l}\text { Chi square value } \\
=14.8 \\
\text { And } p \text { value } \\
=0.005\end{array}$} \\
\hline & Buddhist & 0 & $7(100 \%)$ & 0 & \\
\hline & Christian & $1(100 \%)$ & 0 & 0 & \\
\hline \multirow[t]{3}{*}{ Literacy status } & Illiterate & $1(50 \%)$ & $1(50 \%)$ & $0(0 \%)$ & \multirow{2}{*}{$\begin{array}{l}\text { Chi square value } \\
=2.18 \text { and } \\
\text { p value }=0.702\end{array}$} \\
\hline & Under SLC & $6(16.7 \%)$ & $16(44.4 \%)$ & $14(38.9 \%)$ & \\
\hline & Above SLC & $8(21.6 \%)$ & $14(37.8 \%)$ & $15(40.5 \%)$ & \\
\hline \multirow[t]{3}{*}{ Occupation } & Agriculture & $2(10.5 \%)$ & $9(47.4 \%)$ & $8(42.1 \%)$ & \multirow{3}{*}{$\begin{array}{l}\text { Chi square }= \\
10.95 \text { and } p \text { value } \\
=0.027\end{array}$} \\
\hline & $\begin{array}{l}\text { Business } \\
\text { and Service }\end{array}$ & $5(26.3 \%)$ & $12(63.2 \%)$ & $2(10.5 \%)$ & \\
\hline & Housewife & $8(21.6 \%)$ & $10(27 \%)$ & $19(51.4 \%)$ & \\
\hline \multirow[t]{2}{*}{ Parity } & Parity 2 & $13(18.2 \%)$ & $31(43.7 \%)$ & $27(38 \%)$ & \multirow{2}{*}{$\begin{array}{l}\text { Chi square value } \\
=3.78 \text { and } p \\
\text { value }=\mathbf{0 . 1 5 0}\end{array}$} \\
\hline & $\begin{array}{l}\text { Parity more } \\
\text { than } 2\end{array}$ & $2(50 \%)$ & 0 & $2(50 \%)$ & \\
\hline \multirow[t]{2}{*}{ Income } & $\begin{array}{l}\text { Below Rs } \\
15000\end{array}$ & $12(21.4 \%)$ & $20(35.7 \%)$ & $24(42.9 \%)$ & \multirow[t]{2}{*}{$\begin{array}{l}\text { Chi square test }= \\
2.918 \\
\mathrm{P} \text { value }=0.232\end{array}$} \\
\hline & $\begin{array}{l}\text { Above } \\
\text { Rs } 15000\end{array}$ & $3(15.8 \%)$ & $11(57.9 \%)$ & 5() & \\
\hline
\end{tabular}

Above table shows the association between knowledge of new born care and various demographic variables. There is no any association between Knowledge about newborn care and age of the respondents $(\mathrm{p}=0.1)$. There was approximately equal number of respondents who had the knowledge of newborn care in the variation of age group. The proportion of knowledge of respondents residing in urban and rural are not significantly different $(\mathrm{p}=0.21)$. The proportion of knowledge is significant to the religion $(\mathrm{p}=0.005)$. Likewise, the proportion of knowledge of newborn by occupation is significantly associated $(\mathrm{p}=0.027)$. Literacy status $(\mathrm{p}=. \mathbf{7 0 2})$, parity $(0.15)$ and income $(0.232)$ were also insignificant.

Table 3. Practice of newborn care by postnatal mothers $n=30$

\begin{tabular}{|c|c|c|}
\hline Variables & Frequency & Percent (\%) \\
\hline \multicolumn{3}{|l|}{ General Hygiene } \\
\hline Wash hands before handling the newborn. & 1 & 3.33 \\
\hline Keep eye clean & 28 & 93.3 \\
\hline Keep umblilical cord always clean & 25 & 83.33 \\
\hline Wash hand before handling cord & 19 & 63.33 \\
\hline Wash and clean napkins after each motion & 20 & 66.66 \\
\hline Dry napkin under sunlight & 25 & 83.33 \\
\hline Clean genital after each defecation with wet water on it & 18 & 60 \\
\hline \multicolumn{3}{|l|}{ Breast feeding practices } \\
\hline Breast are clean & 28 & 93.3 \\
\hline Feeding position is appropriate & 25 & 83.33 \\
\hline $\begin{array}{l}\text { Support breast with fingers below and the thumb above while } \\
\text { feeding }\end{array}$ & 6 & 20 \\
\hline Support head of newborn while feeding & 22 & 73.33 \\
\hline Burp baby after feeding & 20 & 66.66 \\
\hline Practice Exclusive Breast Feeding & 18 & 60 \\
\hline \multicolumn{3}{|l|}{ Maintenance of body temperature } \\
\hline Cover head with cap & 30 & 100 \\
\hline Keep baby warm according to room temperature & 28 & 93.33 \\
\hline Properly wrap the baby & 28 & 93.33 \\
\hline Perform Kangaroo Mother Care & 2 & 6.66 \\
\hline
\end{tabular}

Over viewing the practice of mother in newborn general hygiene, reveals $3.33 \%$ of mothers practice washing hand before touching the newborn. Majority of mothers $93.3 \%$ keeps their newborns eye clean. About $83.33 \%$ of newborns umbilical cord was clean. Majority of mothers $63.33 \%$ wash 
hands before handling stump and wash and clean napkins after each motion. About $66.66 \%$ mothers wash and clean napkins after each motion. About $83.33 \%$ practice to dry the napkins under direct sunlight. And about $60 \%$ of mothers, wash newborn's genitals after each defecation with wet cloth.

Regarding breast feeding practices $93.3 \%$ of mothers keep their breast clean before feeding. About $86.66 \%$ of mothers position while feeding was appropriate. Minority of mothers ie: $20 \%$ support breast with fingers below and the thumb above while feeding. Majority of mothers ie: $73.33 \%$ support the head of baby while feeding. About $66 \%$ of mothers burp the baby after feeding and $60 \%$ practice exclusive breast feeding.

Concerning practice related toward maintenance of body temperature of newborn, all of the newborn $100 \%$ was properly wrapped, wore a cap or head was covered and they were kept warm according to room temperature. Minority of mother's $6.6 \%$ practice Kangaroo Mother Care.

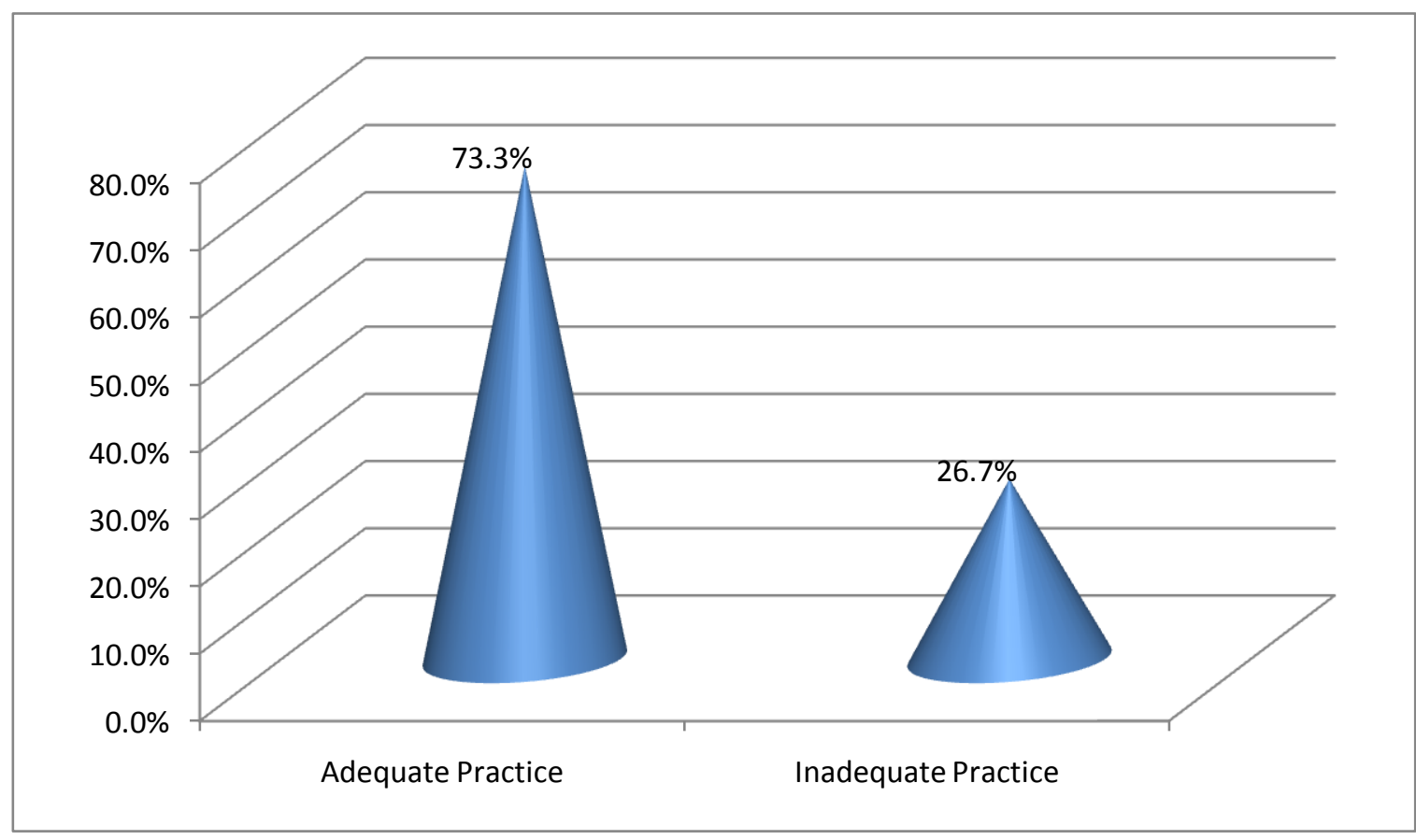

Figure 2. Level of practice of respondents on newborn care

Figure 2 shows that $73.3 \%$ of respondents have adequate practice, $26.7 \%$ have inadequate practice related to newborn care.

\section{DisCUSSION}

This present study mainly focuses to find out the knowledge and practice of newborn care among postnatal mothers. Mothers are the first hand care giver to their newborn so; their knowledge and practices were explored. This study reported that most of the mothers have adequate practice regarding newborn care.

This study found that $41.3 \%$ have moderate knowledge, $38.7 \%$ of respondents have good knowledge, and $20.0 \%$ have poor knowledge related to newborn care. Those who have poor knowledge regarding post natal care need further education. This finding isinconsistence with study done by Reza \& Hassan, 2013. It had found that $78.5 \%$ had moderate, $13.3 \%$ had a good knowledge \& $8.2 \%$ had poor knowledge regarding newborn care. Another study done by Castalino, Nayak\& D'Souza, 2014 states majority $76.6 \%$ of mothers had good knowledge.

Some of the findings of the present study are similar to the previous study. In this present study $73.3 \%$ of respondents have adequate practice, $26.7 \%$ have inadequate practice related to newborn care, which is supported by previous study conducted by Shrestha, Gautam, \&Silwal, 2013, 2013 which states, comparing knowledge with practice regarding newborn care, practice looks better in many areas.

On observation only $3.33 \%$ mothers wash their hand before handling their baby; this may be due to lack of knowledge on importance of washing hand. Therefore education intervention regarding newborn care should be provided during the period of antenatal visit. 


\section{CONCluSion}

Majority postnatal mothers have knowledge on colostrums feeding, eye care, oil massage, cord care and exclusive breast feeding. Regarding practice most of the mothers have adequate practice on newborn care except hand washing and kangaroo mother care. Therefore educational intervention regarding neonatal care is required during the period of antenatal visit. It is a small scale hospital based study therefore large scale hospital base as well as community based study should be carried out to explore the real scenario.

The authors are grateful to MahendraAdarsa Hospital, Chitwan for providing opportunity to collect the data. The authors are also thankful to all post natal mothers who participated in this study.

\section{REFERENCES}

Castalino, F., Nayak, B., \& D'Souza, A. (2014). Knowledge and practices of postnatal mothers on newborn care in Tertiary Care Hospital of Udupi District . Nitte University Journal of Health Science, 98-101.

Monebenimp, F., Mireille, E. M., Chelo, D., Pascal, F., Christopher, K., \& Charles, K. (2013). Mothers' Knowledge and Practice on Essential Newborn Care at Health Facilities in Garoua City, Cameroon. Health Science, 1-6.

Nepal Demographic health Survey. (2011).

Opara, P. I., Jaja, T., Dotimi, A. D., \& Alex Hart, B. A. (2011). Newborn Cord Care Practices amongst Mothers in Yenogoa Local Governmental Area, Bayelsa State, Nigeria. International Journal of Clinical Medicine , 22 - 27.

Reza, S., \& Hassan, E. (2013). Knowledge assessment of neonatal care among postnatal mothers. Iranian Journal of Neonatology, 28-31.

Shrestha, T., Gautam, S. B., \& Silwal, K. (2013). Knowledge and practice of Postnatal mother in Newborn care. Journal of Nepal Medical Association, 372-377.

Thakur, L. S. (2012). Advanced Child Health Nursing. Kathmandu: Ultimate Marketing Pvt. Ltd.

World Health Organization. (2014). Essential Newborn Care. Geneva: WHO/FRH/MSM.

Yadav, M. K. (2013, March). A Study to Assess the Knowledge, Practices and Attitude of Primigravida Mothers on Newborn Care at JJR Maternity Centre. Karnataka, Bangalore, India. 